\title{
DECISION MAKING AND OVERCONFIDENCE: IS THERE A CORRELATION WITH AGE?
}

\author{
Juliana Osmani ${ }^{322}$
}

https://doi.org/10.31410/itema.2018.945

\begin{abstract}
The overconfidence of the decision maker is necessary to achieve good results and could inspire in others a sense of trust, but overconfidence can become an obstacle to decisionmaking process. So, it can create problems for the organization as for example can damage the organization value, can lead to the loss of competitive advantages, reduction of the market share and incomes, weak tendency to innovation, too slow responses to changes, inaccurate risk evaluation, increased risk to bankruptcy etc. If overconfidence is accompanied by excessive optimism, it may become even more dangerous because the decision maker is confident that his abilities are better than those of others, but he is also convinced that the future will be favorable. Decisions taken under these conditions can have bad consequences, both in the economic and non-material aspect.

The main goal of the research is to understand if there is a correlation between overconfidence and age. 210 managers have participated in the study. The intention is to identify variables and elements and to discover possible relationships between them, so as to be able to define some general reflections about the age impact on overconfidence. Starting from previous studies, which show a decline of cognitive and decisional abilities as age advances, it has been hypothesized that the correlation between age and overconfidence is negative. The processing and analysis of the collected data indicate that there is no correlation between these two variables. Thus, overconfidence is independent of age.
\end{abstract}

Keywords: decision-making, age, overconfidence, cognitive abilities, decision-making skills

\section{INTRODUCTION}

$\mathrm{M}$ aking bad decisions can be due to occasional or systematic errors made in any of the stages of the decision-making process [1]. Occasional mistakes may be related to the content of the information and its validity, or may refer to errors in understanding the problem or situation. Systematic errors are cognitive distortions repeated unconsciously. These may also be the result of errors in interpreting information or related to its reliability and accuracy. Cognitive distortions affect the different phases of the decision-making process and have negative effects on human behavior and relationships because they are not easily recognizable and avoidable. One of the cognitive distortions is also overconfidence.

The confidence of the decision maker in his skills is necessary to achieve good results and to inspire confidence in others, but excessive confidence may become a barrier to good decisions [2]. The decision maker that believes in his abilities appears to others as an expert and thus affects their judgments. The bias of overconfidence has a huge influence on the behavior of the decision makers. Due to the excessive belief in personal abilities, the decisions made can be not

\footnotetext{
${ }^{322}$ University “Aleksandër Moisiu” of Durrës, Faculty of Business, Management Department; Address: L.9, Rr:

“AleksandërGoga", P. 979/2, Durrës, Albania
} 
well thought out, hasty or driven by certain emotions that deform reality. If overconfidence is accompanied by excessive optimism, it may become even more dangerous because the decision maker is confident that his abilities are better than those of others but he is also convinced that the future will be favorable. Decisions taken under these conditions can have bad consequences, both in the economic and non-material aspect, negatively affecting the image of the organization, the level of know-how, and so on.

\section{AIM OF THE STUDY AND RESEARCH QUESTION}

The overconfidence of the decision maker is necessary to achieve good results and could inspire in others a sense of trust, but overconfidence can become an obstacle to the decision-making process. So, it can create problems for the organization as for example can damage the organization value, can lead to the loss of competitive advantages, reduction of the market share and incomes, weak tendency to innovation, too slow responses to changes, inaccurate risk evaluation, increased risk to bankruptcy etc.

The main goal of the current research is to understand if there is a correlation between overconfidence and age. 210 managers have participated in the study. The intention is to identify variables and elements and to discover possible relationships between them, so as to be able to define some general reflections about the age impact on overconfidence. To support the main purpose, the research question is as follows:

1. What is the age impact on the overconfidence?

In consistency with the main goal and the research question the hypothesis to be tested is formulated as below:

$\mathrm{H}_{1}$ : The correlation between overconfidence and age is negative.

\section{RESEARCH METHODOLOGY}

For the current study was adopted the quantitative research and for the data collection was used the questionnaire, which was designed to investigate the relationship between overconfidence in the decision-making and age. The model used is the Scale of Rosenberg. This scale is designed to measure the individual's orientation on himself and his perceptions of skills and abilities and is a very useful and widely used global measurement. However, there are some differences from the model of [3]. Thus, the original model includes 10 statements and is based on the Likert scale from 1-4. In the present research only 7 of 8 statements are the same as those of the Rosenberg model and must be evaluated on the Likert scale 1-5.

To test the hypothesis of the research is first used the Pearson correlation coefficient and then is calculated the correlation coefficient of Spearman. The analysis is made on equal-interval scales, based on the sum of the scores for all the statements of the questionnaire.

\section{LITERATURE REVIEW}

Overconfidence is an important aspect that can differentiate adult behavior from that of young people referring to the decision making. However, it must be emphasized that the results of the studies in this regard are not convergent. Previously, [4] and [5] concluded that adults are less 
prone to overconfidence, while [6] consider the opposite. Unlike these conclusions, [7] found the same level of overconfidence in both adults and young people.

The differences between young people and adults about overconfidence can derive from the changes that cognitive and decisional skills endure over time. Once again, it must be emphasized that empirical evidence does not allow definitive conclusions to be drawn. As age advances, the individual undergoes substantial changes regarding the processing speed, memory, reasoning, concentration, and executive functions [8]. It has been shown that these changes move in the opposite direction with age. The decline of the memory and processing speed and also a greater recourse to simpler strategies lead adults to be more incoherent than young people about their decisions [9].

For making decisions, adults consider less information than young people [10]. The more information they have, the more difficult becomes for adults to distinguish between relevant and irrelevant information [11]. Furthermore, the authors suggest that the more experience the decision maker has, the more he relies on pre-built preferences. Based on this assumption, [12] concluded that adult preferences are more stable and help them to quickly identify relevant information. [13] have noted that adults prefer to decide in contexts where there are few possible solutions, while [14] have shown that to eliminate alternatives, adults tend not to consider all the information available. Over time the operational memory is reduced. This leads adults to have difficulty in keeping various information in mind and making comparisons [15].

The impact of age on decision-making can affect the quality of decisions taken [16]. The question that arises is whether really there are differences in the skills and quality of decisions related to age. According to [17] adults adopt different strategies in information processing, but decision-making skills do not become worse. On the other hand, [15] believes that adults tend to avoid decision-making and seek less information, but as age advances we do not have a decline of the decision-making skills, but we can note the use of different strategies and cognitive processes.

When talking about the impact of age on the skills and quality of decisions it might be interesting to consider the relationship between age and wisdom. Defining wisdom is not easy. However, it can be stated that wisdom refers to intelligence and ability to understand complex problems and relationships, and increases following a wide range of positive and negative experiences [18]. In this regard, it could be concluded that adult decision maker are wiser, which means they are able to better understand complex situations and thus make more effective decisions. The empirical evidence is also contradictory in this case. [19] did not found differences between young people and adults. However, adults showed a high level of performance for problems or situations that they considered of particular importance. On the other hand [20] have concluded that as age advances, the decision-making skills become worse and consequently the quality of decisions taken decreases. It has been shown that adult decisions in the financial field are of lower quality than the financial decisions of young people $[16]$.

It is interesting to consider the effect that experience can have on the quality of decisions. In this regard we may think that adults make better decisions than young people because of the higher experience. Again, empirical evidence does not offer definitive conclusions. Thus, [21] argues that competent and more experienced people need the same time as individuals who are new in the workplace to make a decision, but the decision made is better. On the other hand, [22] found a lower decision-making performance in adults with more experience. Adults in 
some circumstances make better decisions than young people because of the higher experience [23].

It must be emphasized that the relationship between overconfidence and age is much more complex than it may seem. Thus, overconfidence does not occur in all situations. To understand this we must refer to the theory of perceived self-efficacy [24]. When a particular decision is placed in a context that is relatively familiar to the decision maker, personal knowledge is favored, which contributes to higher self-efficacy assessments leading to overconfidence. On the contrary, unfamiliar contexts can lead the decision maker to think that does not have the necessary skills to decide effectively, making him underconfident. Thus, the same decision maker can be overconfident about a decision, but can feel underconfident in another situation.

\section{EMPIRICAL APPROACH}

As noted earlier, the relationship age-overconfidence is quite complex. Starting from the results of empirical evidences definitive conclusions cannot be formulated. Some of them report a positive correlation between the two variables, others a negative correlation, and still others no correlation. Taking into consideration also the numerous studies on the relationship between age and cognitive and decisional skills, most of which report a negative correlation between the variables, it has been hypothesized that adults are less overconfident than young people. Thus, the hypothesis to be tested is formulated as follows:

$\mathrm{H}_{1}$ : The correlation between overconfidence and age is negative

Table 1: Pearson correlation coefficient for age-overconfidence

\begin{tabular}{|l|r|r|r|}
\hline & \multicolumn{1}{|c|}{ Value } & df & \multicolumn{1}{|c|}{$\begin{array}{c}\text { Asymp. Sig. } \\
\text { (2-sided) }\end{array}$} \\
\hline Pearson Chi-Square & .971 & 6 & .987 \\
Likelihood Ratio & 1.148 & 6 & .979 \\
Linear-by-Linear Association & .000 & 1 & .985 \\
N of Valid Cases & 210 & & \\
\hline
\end{tabular}

Table 2: Spearman correlation coefficient for age-overconfidence

\begin{tabular}{|c|c|c|c|c|}
\hline & & & $\begin{array}{l}\text { The group of } \\
\text { factors for } \\
\text { Section 1: } \\
\text { Over- } \\
\text { confidence } \\
\text { (summation } \\
\text { at intervals) }\end{array}$ & Age \\
\hline $\begin{array}{l}\text { Spearman's } \\
\text { rho }\end{array}$ & $\begin{array}{l}\text { The group of factors for } \\
\text { Section 1: } \\
\text { Overconfidence } \\
\text { (summation at intervals) } \\
\text { Age }\end{array}$ & $\begin{array}{l}\text { Correlation } \\
\text { Coefficient } \\
\text { Sig. (2-tailed) } \\
\text { N } \\
\text { Correlation } \\
\text { Coefficient } \\
\text { Sig. (2-tailed) } \\
\text { N }\end{array}$ & $\begin{array}{r}1.000 \\
210 \\
-.001 \\
.988 \\
210\end{array}$ & $\begin{array}{r}-.001 \\
.988 \\
210 \\
1.000 \\
210\end{array}$ \\
\hline
\end{tabular}


Referring to Tables 1 and 2 we note a statistically irrelevant relationship between age and overconfidence. The correlation coefficient of Spearman is negative, but shows once again that between the two variables there is no correlation ( $\left.\operatorname{Sig}=p=0.988>0.05 ; r_{s}=-0.001\right)$.

\section{CONCLUSIONS AND FUTURE RESEARCH}

The current research was focused on overconfidence, which is considered an important factor that can influence the decision effectiveness. The basic idea of the study is that a certain level of overconfidence is important to make good decisions, but if we exaggerate then the consequences are negative. More specifically, the current research tries to explore how overconfidence is influenced by age. Starting from previous studies, that show a decline of cognitive and decisional abilities as age advances and that adults are aware of this, it has been hypothesized that the correlation between age and overconfidence is negative. The processing and analysis of the collected data indicate that there is no correlation between these two variables. Thus, overconfidence is independent of age.

It would be interesting to understand the reasons of these results, and then to investigate the topic in depth. For example, we may investigate how experience, the perception of control and self-attribution influence overconfidence.

\section{REFERENCES}

[1] Mariani M. (2009), Decidere e negoziare, Il Sole 24 ORE, Milano

[2] Bazerman M.H., Moore D.A. (2009), Judgment in managerial decision making, $7^{\text {th }}$ edition, New York: John Wiley \& Sons, Inc.

[3] Rosenberg M. (1965), Society and the adolescent self-image, Princeton, NY: Princeton University Press

[4] Devolder P.A. (1993), Adult age differences in monitoring of practical problem-solving performance. In Hershey D.A., Wilson J.A. (1997), op. cit.

[5] Pliske R.M., Mutter S.A. (1996), Age differences in the accuracy of confidence judgments. In Rolison J.J., Hanoch Y., Wood S. (2012), Risky decision making in younger and older adults: The role of learning, Psychology and Aging, Vol. 27, No. 1, pp. 129-140

[6] Crawford J., Stankov L. (1996), Age differences in the realism of confidence judgments: A calibration study using tests of fluid and crystallized intelligence, Learning and Individual Differences, Vol. 6, pp. 84-103

[7] Hershey D.A., Wilson J.A. (1997), Age differences in performance awareness on a complex financial decision-making task, Experimental Aging Research, Vol. 23, pp. 257273

[8] Mienaltowski A. (2011), Everyday problem solving across the adult life span: solution diversity and efficacy, Annals of the New York Academy Sciences, Vol. 1235, pp. 75-85

[9] Finucane M.L., Gullion C.M. (2010), Developing a tool for measuring the decision making competence of older adults, Psychology and Aging, Vol. 25, No. 2, pp. 271-288

[10] Berg C.A., Meegan S., Klaczynski P.A. (1999), Age and experiential differences in strategy generation and information requests for solving everyday problems, International Journal of Behavioral Development, Vol. 23, pp. 615-639

[11] Payne J.W., Bettman J.R., Schkade D.A. (1999), Measuring constructed preferences: Towards a building code, Journal of Risk and Uncertainty, Vol. 19, pp. 243-270

[12] Healey M.K., Hasher L. (2009), Limitations to the deficit attenuation hypothesis: Aging and decision making, Journal of Consumer Psychology, Vol. 19, No. 1, pp. 17-22 
[13] Reed A.E., Mikels J.A., Simon K.I. (2009), Older adults prefer less choice than young adults, Psychology and Aging, Vol. 23, No. 3, pp. 671-675

[14] Riggle E.D.E., Johnson M.M.S. (1996), Age differences in political decision making: Strategies for evaluating political candidates, Political Behavior, Vol. 18, No. 1, pp. 99118

[15] Mather M. (2006), A review of decision making processes: Weighing the risks and benefits of aging. In Carstensen L.L., Hartel C.R. (Eds.), When I'm 64, pp. 145-173, Washington, DC: National Academies Press

[16] Henninger D.E., Madden D.J., Huettel S.A. (2010), Processing speed and memory mediate age related differences in decision making, Psychology and Aging, Vol. 25, No. 2, pp. $262-$ 270

[17] Wood S., Busemeyer J., Koling A., Cox C.R., Davis H. (2005), Older adults as adaptive decision makers: Evidence from the Iowa Gambling Task, Psychology and Aging, Vol. 20, pp. 220-225

[18] Glück J., Bluck S. (2011), Laypeople's conceptions of wisdom and its development: Cognitive and integrative views, The Journals of Gerontology, Vol. 66, No. 3, pp. 321-324

[19] Artistico D., Cervone D., Pezzuti L. (2003), Perceived self-efficacy and everyday problem solving among young and older adults, Psychology and Aging, Vol. 18, No. 1, pp. 68-79

[20] Thornton W.J.L., Dumke H. (2005), Everyday problem solving and decision making in aging: a meta-analytic review, Psychology and aging, Vol. 20, No. 1, pp. 85-99

[21] Patrick J.M.H. (1995), Aging and expertise effects on decision making processes and outcomes. In Thornton W.J.L., Dumke H.A. (2005), op. cit.

[22] Morrow D.G., Menard W.E., Stine-Morrow E.A., Teller T., Bryant D. (2001), The influence of expertise and task factors on age differences in pilot communication, Psychology and Aging, Vol. 16, pp. 31-46

[23] Hertwig R., Barron G., Weber E.U., Erev I. (2004), Decisions from experience and the effect of rare events in risky choice, Psychological Science, Vol. 15, No. 8, pp. 534-539

[24] Cervone D., Artistico D., Berry J. (2006), Self-efficacy processes in adult development. In Hoare C.H. (Eds.), The Oxford handbook of adult development and learning, pp. 167-195, Oxford University Press 
APPENDIX A

\begin{tabular}{|c|c|c|c|c|c|c|}
\hline & $\begin{array}{l}\text { Please, highlight your attitude for each of } \\
\text { the statements below. }\end{array}$ & 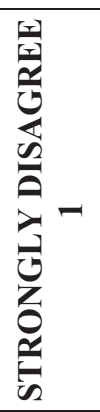 & 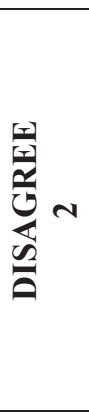 & 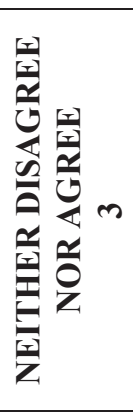 & 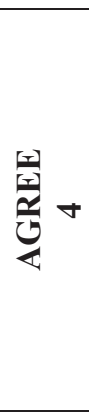 & 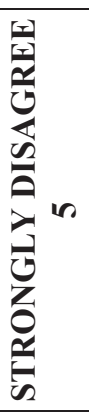 \\
\hline 1. & I feel that I have a number of good qualities. & & & & & \\
\hline 2. & I certainly feel useless at times. & & & & & \\
\hline 3. & $\begin{array}{l}\text { I am able to do things as well as most other } \\
\text { people. }\end{array}$ & & & & & \\
\hline 4. & I feel I do not have much to be proud of. & & & & & \\
\hline 5 . & On the whole, I am satisfied with myself. & & & & & \\
\hline 6. & I wish I could have more respect for myself. & & & & & \\
\hline 7. & I take a positive attitude toward myself. & & & & & \\
\hline 8. & $\begin{array}{l}\text { Within the organization, others have better } \\
\text { decision-making skills than mine. }\end{array}$ & & & & & \\
\hline
\end{tabular}

